\title{
¿EN QUÉ LENGUA SE HABLA HISPANOAMÉRICA?1
}

\author{
por Patricio Marchant ${ }^{2}$
}

Dejar que de una pregunta otras necesariamente se desprendan, unidad de un solo pedir (fragen). Así, si pregunta: ¿en qué lengua se habla Hispanoamérica?, pregunta que, reducida en dos de sus momentos a Chile - problema de espacio y otros-, implica preguntar: a) si acaso existe Filosofía actualmente en Chile; b) si alguna vez ha existido Filosofia en Chile, y c) si puede existir -y de qué modo, según cuál forma- Filosofia en lengua hispanoamericana. $Y$ pregunta que debe trabajar, dejarse trabajar, por la relación entre una lengua particular, la hispanoamericana, y esa otra "lengua", la Filosofía. Esto es, delimitación, los supuestos con los cuales trabajo: de la Filosofia, sus márgenes -me excuso, a lo largo de toda la ponencia, salvo algunas excepciones, de dar las referencias teóricas y bibliográficas precisas, textos que son, o debieran ser, conocidos-; dos conceptos de "Filosofía" operando, por tanto, en lo escrito, y problemas en torno a la cuestión de la Lengua Materna y a la cuestión de la traducción.

Pues si -comenzamos con tesis heideggerianas- la Lengua, y no el hombre es quien habla, si el hombre habla cuando, correspondiendo a lo enviado, nombra, esto es, deja aparecer lo que es, o nombra erigiendo, instituyendo (el judaísmo), la pretensión de pensar desde sí,

\footnotetext{
${ }^{1}$ Esta ponencia fue leída con variantes en el Seminario "Modemidad, posmodernismo: un debate en curso" (Instituto Francés de Cultura, Colegio Autónomo de Filosofia, Taller de Artes Visuales, CENECA y flacso) y en el "Primer Coloquio Chileno-Francés de Filosofía" (Centro de Estudios de la Realidad Contemporánea y Collège International de Philosophie), en junio de 1987.

${ }^{2}$ Patricio Marchant (1939-1990) fue profesor de filosofia del Centro de Estudios Humanísticos de la Facultad de Ciencias Físicas y Matemáticas de la Universidad de Chile. Su obra principal es una interpretación de la poesía de Gabriela Mistral bajo el título Sobre ârboles y madres (Santiago, Gato Murr, 1984) a la que se suman numerosos ensayos, varios de los cuales serán publicados prontamente en el volumen Escritura y Temblor, cuya edición está a cargo de Pablo Oyarzún y Willy Thayer.
} 
desde la conciencia individual y no desde la Lengua, inversión de la relación de soberanía entre la Lengua y el hombre, reducción de la Lengua a medio de comunicación (y de presión), es entonces, ingenuidad de intentar pensar desde lo que Benjamín determina como la concepción burguesa de la Lengua: "Aquella que sostiene que la palabra es un medio de comunicación, su objeto la cosa y su destinatario otro hombre"; a la concepción burguesa del lenguaje, que me sea permitido oponer las filosofias del nombre: Rosenzweig, Heidegger, Benjamín, Lévinas, Derrida. Y afirmación fundamental que adelanto: mientras la cuestión de nuestra - ¿pero qué quiere decir "nuestra"?- Lengua Materna, Lengua Maternal que nos determina, nos destina (Heidegger, obviamente) $o$, Derrida trabajando sobre Heidegger, constituye un "envío", no encuentra la dignidad de su planteamiento, y más de un paso efectivamente cumplido, resultado: esterilidad de los esfuerzos chilenos e hispanoamericanos de aproximación al pensar. Imposibilidad de pensar originalmente; y si lectura de otros textos en otras lenguas, en tanto lectura expresada en español, como traducción al español-europeo, traducción que éste dice resistir, no resiste de hecho.

a) Que no existe actualmente Filosofía en Chile y no exclusivamente a causa del golpe militar y su represión, que no existe desde casi ya cien años, es asunto que cualquiera puede comprobar leyendo las publicaciones teóricas chilenas: conjunto de anotaciones de lecturas, tantas veces anotaciones sobre las notas de anotadores extranjeros - tal vez una única excepción (H.G.) - Ensayos de "Historia de la Filosofia" han existido y existen. Sólo uno de ellos a un nivel "europeo": la neokantiana exposición de Kant de Roberto Torretti. Ciertamente debo dejar a un lado pedantescas obras que ignoran incluso la bibliografía esencial sobre su supuesto tema: así, pretender hablar del poder y la violencia sin conocimiento siquiera de la existencia de Rosenzweig, de Lévinas, etc. Pero, por otra parte, después del golpe militar, comenzaron investigaciones sobre cómo en el siglo pasado y a comienzos de éste se realizó y estructuró la recepción - adecuada y oportuna recepción- en nuestro país de las filosofias de los países teóricamente dominantes y cómo ese saber se institucionalizó; por ejemplo, pero ejemplo que no cabe simplemente en las categorías de "ejemplos", la creación, el sentido, las realizaciones de la ex Universidad de Chile. Investigaciones que estoy lejos de conocer en su totalidad, pero cuyos fundamentos teóricos, si de lo que se trata es de no caer en un mero historicismo - pregunta; ¿qué es lo "político", qué la "violencia", el sentido de poder y el poder del 
sentido (Laruelle), etc.? - no me parecen, en las investigaciones que conozco, debidamente conceptualizados. Pienso lo mismo de ensayos de teoría política en los cuales no se encuentran inscritos los verdaderamente grandes pensadores de siglos pasados o de nuestro siglo.

b) Por otra parte, y en segundo lugar, pregunta de si acaso existió alguna vez Filosofía en Chile, que obliga a responder, mediados y fines de siglo pasado, comienzos de este siglo, en forma positiva; en su forma más alta, en la obra de dos grandes rectores de la ex Universidad del ex Estado de la ex República de Chile: Bello, Letelier. Su escena: filosofias pensadas "idealmente" —en "la vida solitaria del alma" (Husserl), si se quiere - en inglés o francés y, luego, "traducidas" simplemente al español-europeo en el cual sus autores se expresaban. Filosofias que conformaron el Estado chileno, y no sólo en su acción docente. Pero filosofias que pasaron por alto - supuesta "universalidad del espíritu", esto es, dependencia cultural, ¿en este caso o siempre?, la universalidad del espíritu como imperialismo teórico- la más simple de las preguntas: ¿cuál era o, más bien cuál debería ser, porque, de un modo especial y oculto ya lo era, la lengua de Hispanoamérica?

c) Paso a la tercera pregunta. ¿En qué Lengua hablamos nosotros? ¿Cuál es la Lengua, quiénes "somos" "nosotros" cuando decimos: "nosotros"? Historia: hace casi ya quinientos años, feroces carniceros, según el adecuado término de Neruda, hombres de espada y sed de oro - la "santa cultura cristiana occidental", su vocación-, llevaron a cabo el mayor genocidio que conoce la historia: el diecisiete por ciento de la población mundial, setenta millones de indígenas, aniquilados en escasos cincuenta años de horror sin cuenta (Todorov) -sólo otro carnicero podría intentar justificar, cualquiera sea esa justificación, ése, el Gran Holocausto. Si parte importante de los habitantes indigenas mantiene la Lengua, nosotros los mestizos —en el origen, padres españoles, madres indias violadas - hablamos español. Pero rechazo de la concepción vulgar de "mestizo", necesidad de una concepción no-biológica de mestizaje, ¿el español que aprendimos era el mismo que el español de España? Dos versos de Neruda nos marcan un camino, en la medida en que, de ellos, necesidad de hacer su experiencia, a ellos entregarnos, someternos: "Antes de la peluca y la casaca/ fueron los ríos, ríos arteriales" (comienzo del Canto General) y "permanencia de piedras y de silencio" (Alturas de Macchu-Picchu). E intento este paso. En Der Stern der Erlösung Rosenzweig, en oposición total a la totalidad de la Filosofia, a la filosofia como Totalidad, Hegel resumiendo y acabando 
el Discurso Filosófico, discurso, filosofia, que dejan fuera de ella, anulándola, la existencia individual -amor y muerte es ésta, "El amor es tan fuerte como la muerte" - Rosenzweig, digo, muestra cómo la Filosofía recubre y oculta la relación inmediata del hombre consigo mismo, con el Mundo y con Dios. Relación que, conocimiento de los "elementos" o del "pre-mundo", constituye la creencia y su órgano de adecuada y verdadera expresión, el lenguaje común. Y es en la religión judía - la religión como un sentido otro que el sentido que la Filosofía establece como identidad del ser y el pensar- donde Rosenzweig encuentra las categorías fundamentales que dan cuenta de nuestra existencia concreta. Para Rosenzweig sólo la religión griega, el judaísmo y el cristianismo constituyen religiones propiamente tales dignas de ser tomadas en cuenta; igualmente, si el paganismo griego constituye la base de toda historia de esa base. Al paganismo griego la religión judía lo excedería desde sus tres nociones básicas: Creación, Revelación, Redención. Por ello resulta evidente que a partir de Rosenzweig, el gran poema de Neruda en el Canto General, La Huelga "Vi la huelga en los brazos reunidos.../ vi por primera vez lo único vivo/ La unidad de las vidas de los hombres", habría que entenderlo, aunque derivando del marxismo nerudiano, no como un filosofema, sino como un momento judío esencial del marxismo: la Redención mesiánica. Pues la utopía mesiánica del marxismo es parte de nuestro lenguaje, de nuestra existencia personal, una forma, no, por cierto, la única, de la presencia de la Redención en nuestra época.

Rosenzweig y Hegel, Rosenzweig, señalando los conceptos fundamentales de nuestra existencia inmediata y de nuestra existencia superior, como no-filosofemas, ¿escapa, excede realmente el dominio de la filosofia, de la filosofía hegeliana? Pues, así como Derrida leyó a Lévinas, como judaísmo y filosofia, necesidad de leer, tarea no cumplida aún, esa misma problemática en Rosenzweig.

¿Qué pasa con el "antes" de Neruda? ¿Escapa el "antes" de Neruda a la Filosofía y a la Religión? ¿O no consideraría Rosenzweig la "América" sin nombre descrita por el Canto General como una relación -y religión- todavía demasiado elemental? O, más bien, el "antes" de $E l$ Canto describe una primera y permanente relación entre la naturaleza y el hombre anterior al "antes" de Rosenzweig - piénsese por ejemplo, en la transformación que Neruda hace sufrir en la segunda estrofa de Alturas... al verso célebre de Antígona o en este pasaje de la Oda a Lenín: "Lenín atento al bosque y a la vida/ escuchando los pasos del viento y de la historia/ en la solemnidad de la naturaleza". Me veo obligado a 
dejar aquí abierta la cuestión de la "anterioridad" de estos dos "antes", sin sorprenderme demasiado que la seudocrítica filosófica chilena haya pasado por alto este diálogo, a la distancia, no por ello menos real, entre Neruda y Rosenzweig; antecedentes: la crítica chilena se pasó por alto el diálogo de la Mistral con Heidegger y el sicoanálisis, catastrófica situación del discurso "teórico" chileno. Con todo, debo todavía, respecto al "antes" nerudiano, examinar otra posibilidad.

En su artículo de 1985, "Histoire universelle et différences culturelles", Lyotard se pregunta si "podemos actualmente continuar organizando el conjunto de hechos que nos vienen del mundo, humano y no humano, subsumiéndolo bajo la Idea de una historia universal de la humanidad". La pregunta, si bien encuentra su origen en lo que Lyotard considera el fin de los metarrelatos legitimantes de la Modernidad, se refuerza por el estudio de las sociedades primitivas o "salvajes". Éstas, gracias al sistema y a la estructura de sus dispositivos narrativos, relatos que no son propiedad de un sujeto, al contrario, el sujeto es enunciado, es nombrado, recibe de ese dispositivo su legitimación, poseen una identidad cultural, permaneciendo enteramente al margen de una historia en sentido cosmopolita (Kant). "Nada, escribe Lyotard, en la comunidad salvaje la conduce a dialectizarse hacia una sociedad de ciudadanos. Decir que ella es 'humana' y prefigura una universalidad, es admitir el problema (humanismo-historia universal) resuelto". Ahora bien, esta descripción de sociedades primitivas a las que se refiere Lyotard, sudandino-americanas por lo demás eno constituye, su conocimiento, como saber etnográfico, ni poético, ni filosófico ni religioso, el verdadero saber de ese "antes" que poetiza Neruda? No, porque el problema de Neruda es diferente. Neruda habla de una "América" que sabe, a la fuerza, incorporada a la Historia Universal, aunque esa Historia no le sea "propia", y, porque el "antes" que él busca es anterior incluso a cualquier tipo de sociedad: la permanente relación hombre-naturaleza. $\mathrm{Y}$ punto tan importante como el primero, o que coincide con él, Neruda escribe ese "antes", como todo el Canto, como es obvio, en español: en verso y prosa Neruda ha expresado su admiración y amor por el español como Lengua.

¿Entonces, Neruda poeta español, del único español, el español-europeo? Sin embargo... pregunta ¿quién escribe el Canto Generab Si en la relación elemental que el Canto establece como naturaleza-hombre, el río, origen eterno del lenguaje, y la piedra, materia mediante la cual el hombre se eleva como hombre -origen de ambos, origen de todo, el mar, "central volumen de la fuerza"-, el hombre al erguirse como tal 
sólo sabe resguardarse del otro hombre de este modo: destruyéndolos y destruyendo sus obras. Son, entonces, en vez de las ciudades, las ruinas. Neruda ha poetizado al menos en cuatro ocasiones ruinas. Ruinas; ¿queda en esas piedras un resto de palabras, de vida?

Roca religiosa de Rapa Nui, estatuas, moais, naturaleza alzándose sobre sí misma como figura humana, ahora nuevamente naturaleza, ausencia eterna del aquel hombre, su constructor, "mortal picapedrero". Ruinas, piedras que nada pueden decirle al poeta -no le reserva una sílaba el cráter-y que sólo esto expresan; la voluntad general, natural, de permanecer. Neruda no se identifica con Rapa Nui; esas ruinas no son sus ruinas.

Resto del mundo, esplendor, el Partenón, alli el hombre salió "del desorden eterno,/de los grupos hostiles/ de la naturaleza", comenzó a ser hombre, razón: pensamiento que "tuvo continente donde andar y medir". Y así, cuando su abandono, "otra vez creció el terror, la sombra,/ volvió el hombre a vivir en la crueldad". Vigilante fiel a su trabajo, el Inmenso cumplió con su terrible deber de durar: "era lección de piedra, era razón la luz edificada". Con todo, eterno, el hombre volvió al templo, su templo, vacío ya de su "pasajero dios"; pasajero dios: lejanía y cercanía de Neruda a Heidegger.

Ruinas también de España. España redimida - República Española, su nombre - de su antiguo papel bestial de adelantada de la "santa cultura cristiano-occidental", vale decir, para Chile, guardiana de las alpargatas de los Errázuriz, de los calcetines de los Eyzaguirre, sus reyes. España nueva que sufrió, como antes la América sin nombre, el asalto de nuevos, terribles carniceros. Así, lo que fue creado y dominado "yace - pobre pañuelo- entre las olas/ de tierra y negro azufre". Y no se escuchan palabras: "las palabras que tanto construyeron/ ahora son exterminio" y ya naturaleza, musgo, el sollozo. Poeta que, participando del dolor de España, con España no puede, propiamente, dialogar, esto es, identificarse con sus ruinas. ¿Por qué ese diálogo que falta? Falta, como una inmensa falta, la inmensa ascensión, que es una inmersión, en la capital de la derrota, átomo de esperanza, amor, Macchu-Picchu, "permanencia de piedras y de palabra", permanencia de las palabras en las piedras, "una vida de piedra después de tantas vidas". Un "yo" se adelanta, y claridad insuperable su decir: "pared suavizada por el tacto de un rostro que miró con mis ojos/ las lámparas terrestres/ que aceitó con mis manos las desaparecidas maderas". Voz que dice, insisto: " $m i s$ ojos", "mis manos", ninguna metáfora en parte alguna. El poeta es la vida que permanece en las piedras de Macchu-Picchu. Esto es, Neruda, 
todos nosotros, somos mestizos, no como consecuencia de la relación biológica de sangre española-india; en términos adecuados, en términos de Lengua, de nombre, el mestizaje se establece entre la Lengua europea y la Lengua india (como Lengua, no como palabra de una lengua), que Hispanoamérica conserva, cuya permanencia Neruda descubre en Alturas de Macchu-Piccbu. No se trata, como piensa Alain Sicard -en su libro, Sicard reúne los poemas sobre las ruinas- que Neruda haya encontrado en la ascensión - así dice Sicard; no dice "en el poema" -a Macchu-Picbu, las nociones del hombre como trabajador y como explotado o, según otros intérpretes, lo encontrado y descubierto haya sido el hombre en general. En Alturas de Macchu-Piccbu, las piedras de las ruinas le hablan a Neruda, son, de Neruda, "sus", "ruinas", "nuestras" ruinas; piedras y ruinas como Lengua. Por ello, identificación, diálogo y no monólogo con ellas, lo que no sucedió con las ruinas de España ni sucederá con las ruinas de Rapa Nui ni con las del Partenón. De ahí la verdadera significación de los versos famosos: "Yo vengo a hablar por vuestra boca muerta" y "Hablad por mis palabras y mi sangre". El poeta no viene a "representar" - ihasta eso se ha dicho! - a los habitantes de la ciudad sagrada, capital nuestra, mestizos sudamericanos. Su voz es la voz de ellos porque el poeta es, en parte, parte de ellos, vivos en las piedras, vivos en la sangre de nuestro inconsciente - debo un punto esencial de la interpretación de estos versos a Raúl Zurita, si bien sé que hablar de huellas némicas constituye un recurso válido, pero demasiado general: las mediaciones están ahí, en forma diferente según los diferentes países hispanoamericanos.

Todo lo cual significa: la Lengua de Neruda no puede ser la Lengua española-europea. Si lo es al nivel inferior de la comunicación y de la expresión, no lo es si de lo que se trata es de nombrar. Lengua de padre español, Lengua de india violada, la Lengua en que se habla Hispanoamérica es una Lengua fragmentada, violada. No porque, como cree cierta "crítica" universitaria chilena, que en el español-europeo, a diferencia del latinoamericano, las palabras funcionan con un sentido pleno, toda lengua es Lengua violada - violación anasémica, me excuso de comentar los conceptos de Nicolás Abraham. "La castración -que es violación-es la escencia del lenguaje", escribe Abraham. Pero violación que en el caso de la Lengua poética y pensante (cuando la haya) hispanoamericana consiste en una violación que remarca la violación, violación suplementaria, entonces: "lógica del suplemento" que obliga a una defensa extrema y doble.

Lo anterior significa: Hispanoamérica, Latinoamérica, deseo, esto es, 
exigencia de acceder a una Historia cosmopolita (Kant) y no como lo ha sido hasta el momento, elemento, "naturaleza" de la Historia cosmopolita de otros Imperios, debe alcanzar un nombre "propio", nombrarse. Nombrarse, hablarse desde sí misma, para un futuro posible a partir de un futuro posible que un pasado hace posible. Cuestión del nombre que Gabriela Mistral entendió y, explicó hace ya tantos años, comprendidas sus consecuencias, la violencia política: unidad de la raza cumplida por una Lengua común. Y cuestión que comprendieron Vallejo, Neruda ("Tierra mía sin nombre, sin América") o Borges, Borges -ejemplar escritor hispanoamericano- que subvierte el español-europeo desde el inglés o el francés (se sabe, algunos ingenuos han propuesto considerar traducciones de textos de Borges al inglés o al francés como constituyendo los textos originales de Borges); de otro modo, pero como síntoma, el mismo problema de la Lengua, Huidobro escribiendo directamente en francés. Unidad de la raza, de la Lengua Hispanoamericana, me debo limitar aquí, dejando a un lado, cuestiones tan esenciales como las del ritmo de una escritura - ipues el ritmo no es todo en una escritura (Nietzsche)? - a la cuestión del hispanoamericano y la traducción. Por ello no toco problemas que en realidad no son tales, como la introducción de palabras españolas como substitutivas de palabras españolas, o problemas reales como la forma que toma, en este siglo, la mirada hispanoamericana hacia otras Lenguas europeas que la española. Tomo el problema de la traducción por varios motivos:

a) Porque - proposiciones derridareanas - el paso de una Lengua natural a la Filosofía se cumple como traducción: cuestión de la verdad y del sentido, anterior a toda Lengua; de aquéllos, ésta sólo su simple y reemplazable exterioridad. Condición de posibilidad - ilusoria- de la Filosofía.

b) Porque un texto como texto no es enteramente traducible ni enteramente intraducible; más bien, traducible e intraducible al mismo tiempo: Lengua Maternal y agregrados a la Lengua Maternal, lógica de los "agregados".

c) Porque en el proceso de traducción se juega el parentesco entre las Lenguas, la constitución, como idealidad e imposibilidad, de un texto único o sagrado (die reine Spracbe de Benjamín; sé que tendría que explicar cuidadosamente este punto).

d) Porque, contra lo que se piensa comúnmente, en la traducción, no sólo es puesta en cuestión la Lengua en que se traduce sino también 
- cuanto más si se trata de un traductor - se cuestiona, se revela o devela la Lengua que se traduce. Que nos sirva como ejemplo La Voix et le Pbénomène de Derrida. Pues si Bedeuten y Bedeutung eran, y son, entendidas por los alemanes como las palabras, otro "mundo", "significar" y "significación", si Husserl llevó a cabo una meditación de la Bedeutung que lo dejó en el límite de poder entender la Bedeutung como nombre, su "mundo" pleno. Derrida al traducir Bedeutung como vouloir dire, "querer decir", al traducirla como nombre abre el alemán a su propia comprensión como alemán; dice lo no dicho pero implícitamente pensado, esto es, prejuzgado, por el alemán - no sólo en alemán- en cuanto al "sentido" de "significar" y "significación". (Se sabe, Heidegger propone otra lectura de Bedeutung, que no discutiré aquí, en todo caso, Heidegger, es fundamental, traduce el alemán al alemán, a cierto alemán, si se quiere. Dejo de lado, por cierto, tantos otros problemas fundamentales de la traducción, tantos nombres de problemas: Benjamín, Abraham, Torok, Nicolás Rand, Derrida, ciertamente).

De este modo, en la necesaria lucha hispanoamericana contra el español-europeo, necesidad de ser, ser un nombre, reparación de la violación como una "nueva" Lengua, necesidad de un, así llamado, "nombre propio", de una, así llamada, "identidad cultural", de una, así llamada, "historia propia"; esto es, en la medida en que una futura Lengua hispanoamericana debe enfrentarse primera y directamente al español-europeo. Lengua en la cual faltan en absoluto filósofos - Suárez pensó y escribió en latín- o Lengua reducida a "palabras" (medio de comunicación) y no Lengua de nombres, necesidad de una doble tarea: convertir, esto es, traducir, las palabras españolas a nombres, y de revestir las palabras del español-europeo con experiencias o descubrimientos hispanoamericanos. Así Gabriela Mistral tomó la palabra "desolación" para entenderla, toda la enormidad de relaciones conceptuales que ello implica, como descubrimiento o imposición, después de la muerte de un anterior Dios y el silencio de escritura que a esa muerte sigue, de otro Dios, vale decir, de otra escritura; así Neruda y el nombre, así Vallejo y Borges y toda la gran poesía chilena.

De este modo, el proceso de constitución del hispanoamericano, como Lengua distinta al español-europeo, distinta no al nivel de la comunicación, como he insistido, ya ha comenzado. Primero, poéticamente. Ello no sólo porque dichterisch wobnet der Mensch..., sino porque en la poesía el cambio de ritmo propio, negación que es lo "propio" de su ritmo. ¿No resulta entonces necesario intentar directa- 
mente la tarea de la elaboración de un pensar hispanoamericano, "el uso que haces de tu lengua se me aparece como un reproche al triste francés universitario en que me refugio", palabras de Claude Imbert.

Quisiera, finalmente, dejar abierta la cuestión del momento mesiánico presente en nuestro hablar común - por ejemplo, este Seminario- en nuestro chileno absurdo intento por continuar existiendo como país cuando todo es derrota política, miseria económica, ignorancia, comedia incluso. Ese momento mesiánico ies un momento que la Filosofía ha absorbido ya, negándolo al incorporarlo como un momento indecidible para la Filosofia? Indecidible, vale decir — ¿en este caso o en sí?-, momento no "filosófico", momento ético, más exactamente, el "antes" a toda ética posible (Lévinas, Derrida, Jean-Luc Nancy). Única justificación posible de la realización de este seminario al menos para mí. 